\title{
Racial differences in diabetes-related psychosocial factors and glycemic control in patients with type 2 diabetes
}

This article was published in the following Dove Press journal:

Patient Preference and Adherence

19 August 2010

Number of times this article has been viewed

\author{
Leslie RM Hausmann' \\ Dianxu Ren² \\ Mary Ann Sevick 1,3,4,5 \\ 'Center for Health Equity Research \\ and Promotion, ${ }^{3}$ Geriatric Research \\ Education and Clinical Center, \\ VA Pittsburgh Healthcare System, \\ Pittsburgh, PA, USA; ${ }^{2}$ School of \\ Nursing, ${ }^{4}$ School of Medicine, \\ ${ }^{5}$ Graduate School of Public Health, \\ University of Pittsburgh, Pittsburgh, \\ PA, USA
}

Background: We examined whether diabetes-related psychosocial factors differ between African American and white patients with type 2 diabetes. We also tested whether racial differences in glycemic control are independent of such factors.

Methods: Baseline glycosylated hemoglobin $\left(\mathrm{HbA}_{1 \mathrm{c}}\right)$ and survey measures from 79 African American and 203 white adult participants in a diabetes self-management clinical trial were analyzed.

Results: Several psychosocial characteristics varied by race. Perceived interference of diabetes with daily life, perceived diabetes severity, and diabetes-related emotional distress were higher for African Americans than for whites, as were access to illness-management resources and social support. Mean $\mathrm{HbA}_{1 \mathrm{c}}$ levels were higher among African Americans than whites $(8.14$ vs 7.40 , beta $=0.17)$. This difference persisted after adjusting for demographic, clinical, and diabetes-related psychosocial characteristics that differed by race (beta $=0.18$ ). Less access to illness-management resources (beta $=-0.25)$ and greater perceived severity of diabetes (beta $=0.21$ ) also predicted higher $\mathrm{HbA}_{1 \mathrm{c}}$.

Discussion: Although racial differences in diabetes-related psychosocial factors were observed, African Americans continued to have poorer glycemic control than whites even after such differences were taken into account. Interventions that target psychosocial factors related to diabetes management, particularly illness-management resources, may be a promising way to improve glycemic control for all patients.

Keywords: diabetes mellitus, type 2, minority health, health status disparities, psychosocial factors, disease management

An estimated 17.9 million people in the United States had a diagnosis of diabetes in 2007, with direct and indirect costs associated with diabetes totalling \$174 billion. ${ }^{1}$ The burden of this prevalent and costly disease falls disproportionately on African Americans, with recent estimates indicating that $14.7 \%$ of non-Hispanic African American adults have diabetes, compared with $9.8 \%$ of non-Hispanic whites. ${ }^{1}$ Not only is diabetes more prevalent among African Americans, ${ }^{2-6}$ but among those diagnosed with diabetes, African Americans are less likely than whites to achieve adequate control of blood glucose levels ${ }^{7-19}$ and are more likely than whites to suffer diabetesrelated complications such as nephropathy, end-stage renal disease, retinopathy, lower-extremity amputations, and mortality. ${ }^{15,20-30}$

Given that maintaining near-normal levels of blood glucose can greatly reduce the risk of experiencing diabetic complications, ${ }^{31}$ it is important to understand why disparities exist in glycemic control. Identifying factors that facilitate or hinder effective
Correspondence: Leslie RM Hausmann VA Pittsburgh Healthcare System, Center for Health Equity Research and Promotion, 7I80 Highland Drive (I5IC-H), Pittsburgh, PA I 5206, USA Tel + I 4I2954522I

Fax + I 4129545264

Email leslie.hausmann@va.gov. 
diabetes management, and determining whether these factors operate the same for African American and white patients, would allow the strategic development and implementation of interventions designed to reduce disparities between groups. However, few factors underlying the racial gap in glycemic control have been identified. Several studies have shown that racial differences in glycemic control persist after controlling for demographic, clinical, and behavioral factors such as age, sex, body mass index, education, socioeconomic status, physical comorbidities, depression, diabetes treatment regimen, access to health care, adherence to diabetes medications, and physical activity levels. ${ }^{7,8,11-13,16,32-34}$ Racial differences in glycemic control are also not fully explained by differences in processes of care, as rates of obtaining standard tests and screenings for comprehensive diabetes management are often equivalent or higher for African Americans compared with whites. ${ }^{10,15,35-41}$

Achieving and maintaining adequate glycemic control can require the adoption of multiple behaviors that involve diet, exercise, and appropriate intake of insulin and/or oral hypoglycemic medications, resulting in a complicated regimen that poses significant challenges to patients. Social cognitive theory (SCT) maintains that whether patients adopt desired behaviors is influenced by the interaction of intrapersonal factors (eg, belief in one's ability to adopt the behavior or the expected utility of adopting the behavior) and environmental factors (eg, social support for the behavior or lack of external barriers). ${ }^{42}$ The basic tenets of SCT are supported by a large body of evidence showing that factors such as self efficacy in disease management and social support are associated with increased adherence to recommended diabetes self-management behaviors and improved glycemic control. ${ }^{43-48}$ Much of the early work applying SCT to diabetes management, however, did not examine whether there were racial differences in intrapersonal and environmental factors related to diabetes management (heretofore referred to as diabetes-related psychosocial factors) or whether such factors had different effects on diabetes outcomes for these groups.

More recent work has begun to focus on whether the tenets of SCT generalize to diabetes management among African American patients, but studies have yielded mixed results. ${ }^{49-54}$ The influence of social support and self efficacy on various self-care domains has been inconsistent in African American samples, with some studies finding no relationships ${ }^{54}$ and others finding relationships with some, but not all, self-care domains (eg, glucose monitoring and exercise, but not medication adherence). ${ }^{49,50,53}$ There is also evidence that diabetes-related emotional distress, which may interfere with diabetes management behaviors, is not related to glucose control among African Americans. ${ }^{55}$ However, few studies have directly examined whether diabetes-related psychosocial factors such as these differ between African Americans and whites or whether racial differences in glycemic control persist after taking into account racial differences in diabetes-related psychosocial factors.

We attempted to address this gap in the literature by exploring whether racial differences exist for several psychosocial factors found in past research to be associated with improved diabetes self-care and/or glycemic control. These included factors pertaining to self-care and quality of life (eg, self-efficacy in diabetes self-management, diabetesrelated social support, perceived severity of one's disease), access to resources that support disease management, and emotional distress related to diabetes. We further examined whether racial differences in glycemic control remained after taking into account race differences in these factors. We examined these issues using baseline data from African American and white patients enrolled in a clinical trial of a behavioral intervention to improve diabetes self-management.

\section{Methods}

\section{Patient population}

Data for this analysis consisted of baseline measures collected from patients enrolled in the ENHANCE study, a single-center, randomized controlled trial of a behavioral intervention designed to foster adherence of individuals with type 2 diabetes to their self-management regimen. Participants were recruited from Pittsburgh, Pennsylvania and the surrounding area. Adults with a self-reported diagnosis of type 2 diabetes were eligible for enrollment in the trial. Exclusion criteria included (1) history of hypoglycemic coma/seizure within the last 12 months, (2) hypoglycemia requiring 3 rd party assistance within the last 3 months, (3) unwillingness to do capillary blood testing, (4) history consistent with type 1 diabetes, (5) unwillingness or inability to participate in scheduled group classes, (6) renal dialysis or expectation of dialysis within the next 6 months, (7) history of dementia, alcohol, or substance abuse, (8) plans to move outside of the study region within the next 8 months, and (9) participation in another clinical study. Eligible participants were scheduled for a baseline fasting laboratory measurement visit and completed a baseline survey (described below). Data collected from participants during their baseline visit were used in the current analyses. Complete details regarding the intervention and study design are available elsewhere. ${ }^{56}$ 


\section{Measurements}

Two weeks prior to their baseline assessment visit, eligible participants were sent a packet of questionnaires that contained measures of demographic, clinical, and diabetesrelated psychosocial factors used in the current analyses. Demographic and clinical factors included self-reported race and ethnicity, gender, years of formal education, annual household income, employment status, health insurance status, and diabetes medication regimen (coded as 'includes insulin vs does not include insulin' for analyses). Total caloric expenditure through physical activity was also assessed using the Community Health Activities Model Program for Seniors questionnaire (CHAMPS). ${ }^{57}$ Physical and mental comorbidities were assessed using the Rigler comorbidity checklist $^{58}$ and Beck Depression Inventory-II, ${ }^{59}$ respectively. Descriptions of the diabetes-related psychosocial factors and how they were measured are provided in Table 1.

During the baseline assessment visit, signed informed consent was obtained, after which questionnaires were collected and reviewed for completeness. Staff also obtained measures of height and weight at that time, which were used to calculate body mass index (BMI). Glycemic control was determined by serum hemoglobin $\mathrm{A} 1 \mathrm{c}\left(\mathrm{HbA}_{1 \mathrm{c}}\right)$ levels obtained via venipuncture. At the completion of the baseline visit, participants were given a $\$ 20$ gift certificate to a local grocery store and parking vouchers or bus passes were provided as needed. The study was approved by the Institutional Review Board of the University of Pittsburgh.

\section{Statistical analysis}

We first determined whether there were significant $(P<0.05)$ racial differences in each demographic, clinical, and diabetes-related psychosocial factor by examining bivariate associations between race and each variable. Continuous variables were summarized using means and standard deviations; categorical variables were summarized by frequencies and percentages. Bivariate associations between race and each variable were assessed using Student's $t$-test or its nonpara-

Table I Summary of psychosocial measures

\begin{tabular}{|c|c|c|c|c|c|}
\hline Variable & Description & $\begin{array}{l}\text { Measurement } \\
\text { tool }\end{array}$ & \# of items & $\begin{array}{l}\text { Possible } \\
\text { range }\end{array}$ & $\begin{array}{l}\text { Cronbach's } \\
\text { alpha }\end{array}$ \\
\hline $\begin{array}{l}\text { Access to illness- } \\
\text { management resources }\end{array}$ & $\begin{array}{l}\text { Support (eg, informational or emotional) } \\
\text { for the management of chronic illness } \\
\text { available from one's physician/health care } \\
\text { team, family/friends, personal actions, } \\
\text { neighborhood, community, media/policy, } \\
\text { community organizations, and workplace }\end{array}$ & CIRS $^{65}$ & 64 & $I-5$ & 0.91 \\
\hline $\begin{array}{l}\text { Interference of } \\
\text { diabetes with daily life }\end{array}$ & $\begin{array}{l}\text { Interference caused by diabetes to daily } \\
\text { activities, work, and social/recreational } \\
\text { activities }\end{array}$ & MDQ Subscale 45 & 9 & $0-6$ & 0.93 \\
\hline $\begin{array}{l}\text { Perceived severity } \\
\text { of diabetes }\end{array}$ & $\begin{array}{l}\text { Extent to which diabetes is a severe } \\
\text { health problem and causes concern/worry }\end{array}$ & MDQ Subscale ${ }^{45}$ & 3 & $0-6$ & 0.87 \\
\hline $\begin{array}{l}\text { Perceived diabetes- } \\
\text { related social support }\end{array}$ & $\begin{array}{l}\text { Social support received from significant } \\
\text { others, family, friends, and health } \\
\text { professionals }\end{array}$ & MDQ Subscale ${ }^{45}$ & 4 & $0-6$ & 0.74 \\
\hline $\begin{array}{l}\text { Positive reinforcing } \\
\text { behaviors }\end{array}$ & $\begin{array}{l}\text { Reinforcement received from significant } \\
\text { others for engaging in desirable } \\
\text { self-management behaviors }\end{array}$ & MDQ Subscale ${ }^{45}$ & 8 & $0-6$ & 0.91 \\
\hline $\begin{array}{l}\text { Misguided support } \\
\text { behaviors }\end{array}$ & $\begin{array}{l}\text { Nonsupportive behaviors by significant } \\
\text { others to encourage self-management } \\
\text { behaviors (eg, nagging) }\end{array}$ & MDQ Subscale ${ }^{45}$ & 4 & $0-6$ & 0.82 \\
\hline $\begin{array}{l}\text { Self efficacy in diabetes } \\
\text { self management }\end{array}$ & $\begin{array}{l}\text { Confidence in ability to perform } \\
\text { desirable self-management behaviors }\end{array}$ & MDQ Subscale ${ }^{45}$ & 7 & $0-100$ & 0.91 \\
\hline $\begin{array}{l}\text { Outcome expectancies } \\
\text { for self-care behaviors }\end{array}$ & $\begin{array}{l}\text { Perceptions of the effects of desirable } \\
\text { self-management behaviors on metabolic } \\
\text { control and prevention of complications }\end{array}$ & MDQ Subscale ${ }^{45}$ & 6 & $0-100$ & 0.88 \\
\hline $\begin{array}{l}\text { Diabetes-related } \\
\text { emotional distress }\end{array}$ & $\begin{array}{l}\text { Emotional responses to issues unique } \\
\text { to living with diabetes }\end{array}$ & PAID $^{66}$ & 20 & $0-100$ & 0.94 \\
\hline
\end{tabular}

Abbreviations: CIRS, Chronic Illness Resources Survey; MDQ, Multidimensional Diabetes Questionnaire; PAID, Problem Areas in Diabetes Scale. 
metric equivalent (eg, Wilcoxon rank sum test) for continuous variables and by the $\chi^{2}$ statistic for categorical variables.

Next, we used linear regression to examine whether race was associated with $\mathrm{HbA}_{1 \mathrm{c}}$ level prior to adjusting for any additional variables. We then examined multiple linear regression models to determine whether race was associated with $\mathrm{HbA}_{1 \mathrm{c}}$ level after adjustment for variables that were found to differ by race in the bivariate analyses at a $P$ value of at least marginal significance $(P<0.10)$. The first multivariable model included race and patient demographic and clinical factors that differed by race. The second multivariable model consisted of the first model plus the psychosocial factors that differed by race. Finally, we examined an additional set of models that tested the interaction effects of race and each variable on $\mathrm{HbA}_{1 \mathrm{c}}$ to determine whether the effects of these variables on glycemic control differed for African American and white patients. All analyses were performed using SAS software (version 9.2; SAS Institute, Cary, NC, USA).

\section{Results}

\section{Racial differences in demographic and clinical characteristics}

African Americans and whites differed on several demographic and clinical characteristics (Table 2). Compared with whites, African Americans were significantly younger (mean age $=51.1$ vs 57.3 ), had fewer years of education
(13.4 vs 15.0), expended more calories during physical activity (4228.3 vs 3354.8), and had fewer comorbid conditions (3.3 vs 3.9). There was a marginal trend for African Americans to score higher than whites on the Beck Depression Index (0.6 vs 0.5). African Americans were also more likely than whites to be female $(79.8 \%$ vs $62.7 \%)$ and had lower incomes than whites $(51.3 \%$ vs $19.5 \%$ had incomes $<$ US\$20K). There were no racial differences in body mass index, likelihood of being employed, having health insurance, or having a diabetes-medication regimen that included insulin.

\section{Racial differences in psychosocial characteristics}

African Americans and whites differed significantly on several diabetes-related psychosocial characteristics (see Table 3). Compared with whites, African Americans reported more interference of diabetes with daily life, greater severity of diabetes, and more diabetes-related emotional distress. In contrast, African Americans reported having access to more resources to support illness management and more diabetes-related social support. African Americans and whites did not differ in positive reinforcing behaviors or misguided support behaviors from significant others, or on levels of self efficacy or outcome expectancies for diabetes self-care behaviors.

Table 2 Demographic and clinical characteristics of white and African American adults with type 2 diabetes

\begin{tabular}{|c|c|c|c|c|c|}
\hline \multirow[b]{2}{*}{ Age (mean $\pm S D)$} & \multicolumn{2}{|c|}{ Non-hispanic white $(n=203)$} & \multicolumn{2}{|c|}{ African American $(n=79)$} & \multirow{2}{*}{$\begin{array}{l}P^{a} \\
0.001\end{array}$} \\
\hline & 57.3 & \pm 11.1 & 51.1 & \pm 8.9 & \\
\hline Years of formal education & 15.0 & \pm 3.0 & 13.4 & \pm 2.4 & 0.0001 \\
\hline Body mass index & 34.6 & \pm 7.0 & 35.3 & \pm 9.5 & 0.55 \\
\hline Caloric expenditure/week & 3354.8 & \pm 2612.9 & 4228.3 & \pm 3175.5 & 0.03 \\
\hline Comorbidity disease index & 3.9 & \pm 2.1 & 3.3 & \pm 2.0 & 0.02 \\
\hline Beck's depression index & 0.5 & \pm 0.4 & 0.6 & \pm 0.5 & 0.08 \\
\hline Women (n \%) & 126 & $62.7 \%$ & 63 & $79.8 \%$ & 0.006 \\
\hline Income & & & & & 0.0001 \\
\hline Less than $\$ 20,000$ & 38 & $19.5 \%$ & 40 & $51.3 \%$ & \\
\hline$\$ 20,000-\$ 50,000$ & 87 & $44.6 \%$ & 23 & $29.5 \%$ & \\
\hline Greater than $\$ 50,000$ & 70 & $35.9 \%$ & 15 & $19.2 \%$ & \\
\hline Employment status & & & & & 0.34 \\
\hline Employed & 122 & $60.7 \%$ & 43 & $54.4 \%$ & \\
\hline Not employed & 79 & $39.3 \%$ & 36 & $45.6 \%$ & \\
\hline Health insurance status & & & & & 0.91 \\
\hline Insured & 190 & $94.5 \%$ & 74 & $94.9 \%$ & \\
\hline Not insured & 11 & $5.5 \%$ & 4 & $5.1 \%$ & \\
\hline Medication regimen & & & & & 0.28 \\
\hline Includes insulin & 37 & $19.4 \%$ & 19 & $25.3 \%$ & \\
\hline Does not include insulin & 154 & $80.6 \%$ & 56 & $74.7 \%$ & \\
\hline
\end{tabular}

Notes: ${ }^{a}$ Comparisons between white and African American participants were made using $t$-tests (or non-parametric equivalent) for means and $\chi^{2}$ tests for frequencies. 
Table 3 Psychosocial characteristics (mean \pm SD) of white and African American patients with type 2 diabetes

\begin{tabular}{|c|c|c|c|c|c|}
\hline \multirow[b]{2}{*}{ Access to illness-management resources } & \multicolumn{2}{|c|}{ Non-hispanic white } & \multicolumn{2}{|c|}{ African American } & \multirow{2}{*}{$\frac{P^{\mathbf{a}}}{0.0005}$} \\
\hline & 2.5 & \pm 0.5 & 2.8 & \pm 0.6 & \\
\hline Interference of diabetes with daily life & 1.3 & \pm 1.3 & 1.7 & \pm 1.4 & 0.01 \\
\hline Perceived severity of diabetes & 3.3 & \pm 1.7 & 3.8 & \pm 1.8 & 0.04 \\
\hline Perceived diabetes-related social support & 3.2 & \pm 1.5 & 3.6 & \pm 1.4 & 0.047 \\
\hline Positive reinforcing behaviors & 2.1 & \pm 1.6 & 2.5 & \pm 1.9 & 0.16 \\
\hline Misguided support behaviors & 1.9 & \pm 1.7 & 2.4 & \pm 2.0 & 0.17 \\
\hline Self-efficacy in diabetes self-management & 40.7 & \pm 20.0 & 38.1 & \pm 19.5 & 0.35 \\
\hline Outcome expectancies for self-care behaviors & 61.4 & \pm 7.9 & 59.9 & \pm 12.1 & 0.31 \\
\hline Diabetes-related emotional distress & 33.4 & \pm 20.8 & 40.1 & \pm 22.9 & 0.02 \\
\hline
\end{tabular}

Notes: a Comparisons between white and African American participants were made using $t$-tests (or nonparametric equivalent).

\section{Race differences in $\mathrm{HbA}_{\mathrm{Ic}}$}

African Americans $($ mean $=8.14$, standard deviation $=2.53$ ) had significantly higher $\mathrm{HbA}_{1 \mathrm{c}}$ levels than whites (mean $=7.40$, standard deviation $=1.71$ ) in analyses not adjusting for any demographic, clinical, or psychosocial characteristics (standardized beta $=0.17, P<0.01)($ Table 4 , Model 1$)$. This race difference persisted after adjusting for demographic and clinical factors that varied by race in bivariate analyses (standardized beta $=0.15, P=0.02$ ) (Table 4, Model 2). In a model that also included diabetes-related psychosocial factors that differed by race, race continued to be a significant predictor of $\mathrm{HbA}_{\mathrm{lc}}$ (standardized beta $\left.=0.18, P<0.01\right)($ Table 4, Model 3$)$. In this model, access to illness-management resources was negatively associated with $\mathrm{HbA}_{1 \mathrm{c}}$ (standardized beta $=-0.25$, $P<0.01)$ and perceived severity of diabetes was positively associated with $\mathrm{HbA}_{1 \mathrm{c}}$ (standardized beta $=0.21, P=0.02$ ). $\mathrm{HbA}_{\mathrm{lc}}$ was not associated with interference of diabetes with daily life, diabetes-related social support, or diabetes-related emotional distress in the final adjusted model. We ran a series of additional models to test whether there were significant

Table 4 Multiple linear regression models examining the association of race with $\mathrm{HbA}_{\mathrm{lc}}$ after adjusting for demographic, clinical, and diabetes-related psychosocial factors that differ by race

\begin{tabular}{|c|c|c|c|c|c|c|c|c|c|c|c|c|}
\hline \multirow[t]{2}{*}{ Variables } & \multicolumn{4}{|c|}{ Model I: race } & \multicolumn{4}{|c|}{$\begin{array}{l}\text { Model 2: model I + demographic } \\
\text { and clinical factors }\end{array}$} & \multicolumn{4}{|c|}{$\begin{array}{l}\text { Model 3: model } 2+\text { diabetes- } \\
\text { related psychosocial factors }\end{array}$} \\
\hline & B & SE & Beta & $P$ & B & SE & Beta & $\mathbf{P}$ & B & SE & Beta & $P$ \\
\hline African American & 0.73 & 0.26 & 0.17 & $<0.01$ & 0.69 & 0.30 & 0.15 & 0.02 & 0.82 & 0.31 & 0.18 & $<0.01$ \\
\hline Age & & & & & -0.008 & 0.01 & -0.05 & 0.50 & 0.005 & 0.01 & 0.03 & 0.68 \\
\hline Years of formal education & & & & & -0.0003 & 0.04 & -0.0004 & 1.00 & 0.01 & 0.04 & 0.02 & 0.81 \\
\hline $\begin{array}{l}\text { Caloric expenditure/ } \\
\text { week (Kcal) }\end{array}$ & & & & & -0.09 & 0.04 & -0.13 & 0.04 & -0.06 & 0.05 & -0.08 & 0.22 \\
\hline Comorbidity disease index & & & & & -0.13 & 0.06 & -0.14 & 0.04 & -0.16 & 0.07 & -0.17 & $<0.0$ I \\
\hline Beck's depression index & & & & & 0.67 & 0.30 & 0.15 & 0.03 & 0.13 & 0.35 & 0.03 & 0.71 \\
\hline Women & & & & & -0.19 & 0.27 & -0.05 & 0.47 & -0.22 & 0.28 & -0.05 & 0.42 \\
\hline Income & & & & & & & & 0.45 & & & & 0.54 \\
\hline$\$ 20,000-\$ 50,000$ & & & & & 0.41 & 0.31 & 0.10 & 0.19 & 0.31 & 0.31 & 0.07 & 0.32 \\
\hline Greater than $\$ 50,000$ & & & & & 0.28 & 0.34 & 0.06 & 0.41 & 0.07 & 0.34 & 0.02 & 0.84 \\
\hline $\begin{array}{l}\text { Access to illness- } \\
\text { management resources }\end{array}$ & & & & & & & & & -0.95 & 0.30 & -0.25 & $<0.01$ \\
\hline $\begin{array}{l}\text { Interference of diabetes } \\
\text { with daily life }\end{array}$ & & & & & & & & & 0.02 & 0.12 & 0.01 & 0.87 \\
\hline $\begin{array}{l}\text { Perceived severity } \\
\text { of diabetes }\end{array}$ & & & & & & & & & 0.25 & 0.10 & 0.21 & 0.02 \\
\hline $\begin{array}{l}\text { Perceived diabetes-related } \\
\text { social support }\end{array}$ & & & & & & & & & 0.08 & 0.10 & 0.06 & 0.44 \\
\hline $\begin{array}{l}\text { Diabetes-related } \\
\text { emotional distress }\end{array}$ & & & & & & & & & -0.0008 & 0.009 & -0.008 & 0.93 \\
\hline
\end{tabular}

Abbreviations: B, unstandardized regression coefficient; SE, standard error; Beta, standardized regression coefficient. 
interactions between race and each of the demographic, clinical, or diabetes-related psychosocial factors that were included in the multivariable analyses. No interactions were significant (data not shown), indicating that the associations between each variable and $\mathrm{HbA}_{1 \mathrm{c}}$ were similar across the two racial groups.

\section{Discussion}

The current study examined whether African American and white patients with type 2 diabetes differ on diabetes-related psychosocial factors, and whether race differences in glycemic control persist after taking into account such differences. We found race differences in some, but not all psychosocial factors examined in this study. Compared with whites, African Americans reported more interference of diabetes with daily life, greater severity of diabetes, and more diabetes-related emotional distress. However, African Americans may have more supportive environments to help them cope, as they reported more overall access to support resources to help them manage their illness and more diabetes-related social support from their family, friends, and health professionals. Interestingly, African Americans and whites did not differ on self-management self-efficacy or perceived benefits of engaging in self-care behavior. This pattern of results suggests that coping with diabetes may pose more challenges for African Americans than for whites, but that African Americans may have more supportive environments than whites to help them cope, and that both groups have equal confidence in their ability to manage their disease and the utility of doing so.

That being said, we found that African Americans had higher $\mathrm{HbA}_{\mathrm{lc}}$ levels than whites, even after controlling for racial differences in the diabetes-related psychosocial factors noted above. This suggests that the persistent race disparity in glycemic control is independent of diabetesrelated psychosocial factors such as support received from significant others or the broader community, self efficacy in diabetes management, beliefs about the utility of engaging in recommended self-care behaviors, interference of the disease with daily life, or distress caused by the disease. Even though race differences were found in some of these areas, the race difference in glycemic control was still observed after taking those psychosocial factors into account.

Explanations for the race difference in glycemic control therefore remain elusive. Recent work has emphasized the role of socioeconomic status (SES) on diabetes prevalence, as SES is often confounded with race. ${ }^{60-62}$ For instance, in a sample of white, African American, and Hispanic adults, race differences in diabetes prevalence were greatly reduced after controlling for a combination of education and income. ${ }^{61}$ Moreover, no racial differences in diabetes prevalence were found in a sample of African American and white adults drawn from a racially integrated urban community where members of both races lived in similar social conditions and did not differ in socioeconomic status. ${ }^{62}$ The current study, which focused on glycemic control rather than diabetes prevalence, found that race differences in glycemic control persisted even after controlling for education and income, demographic characteristics that serve as indicators of SES. It is possible, however, that our measures of SES did not capture other important racial differences in life circumstances that affect glycemic control. For instance, African American and white patients in the current study were likely drawn from poorly integrated communities, as rates of racial segregation remain high in many Pittsburgh neighborhoods. Residential segregation has been proposed as a contributing factor to racial disparities in health, given that it leads to differences in access to high-quality health care, exposure to environmental hazards, access to healthy and unhealthy foods, and recreational facilities that promote physical activity, all of which can influence health. ${ }^{63}$ Additional research is needed to determine whether environmental factors not examined in the current analysis contribute to race disparities in glycemic control.

Even though this study found that the race disparity in glycemic control was independent of diabetes-related psychosocial factors, its results can inform the development of interventions to improve diabetes management for both African American and white patients. Our findings suggest that interventions may not need to be designed to target different psychosocial factors for African Americans and whites. Our results indicate that access to illnessmanagement resources is related to glycemic control for both African Americans and whites. Interventions designed to increase access to support from a variety of sources ranging from close friends and family to more distal sources such as the workplace, community, and the media may be a promising way to improve glycemic control for all patients. Such resources may already be more available to African Americans than whites, as African Americans reported more access to illnessmanagement resources than whites in the current study, and a similar trend has been reported in a previous study with a much smaller sample. ${ }^{64}$ The relatively greater 
access to resources reported by African Americans in the current study may reflect the effects of multiple community-based programs designed to provide African American communities in Pittsburgh with support related to chronic disease management, disease prevention, and promotion of healthy lifestyles. The task of optimizing the impact of such resources on glycemic control remains an important area for future efforts.

The current study has several limitations. First, the sample consisted of patients who self-selected into a study of a behavioral intervention designed to improve diabetes self-management. Therefore, the study sample may not be representative of the general population of patients with diabetes in terms of disease severity or motivation to engage in diabetes self-care behaviors. Second, while the study recruited the expected number of African Americans given the race distribution in the region, the number of African Americans in the sample is small, limiting the generalizability of the findings. Finally, the cross-sectional nature of the study prevents conclusions about causal relationships between the variables examined. For example, it is possible that having poorly controlled diabetes may lead patients to perceive their disease as more severe rather than poor glycemic control being caused by perceptions that one's disease is severe.

Despite these limitations, the current study adds to existing literature by identifying differences and similarities in diabetes-related psychosocial factors across African American and white patients with diabetes, and by showing that the race disparity in glycemic control is independent of differences in such factors. Access to illness-management resources is associated with better glycemic control for both African Americans and whites, which suggests one potential area for the development of interventions to improve diabetes management.

\section{Acknowledgments}

The work of this paper was supported by the following grants: NIH/NINR/NR-R01008792, NIH/NCRR/CTSA-UL1RR024153, and NIH/NCRR/GCRC-M01- RR000056. This material is also the result of work supported by resources and the use of facilities at the Veterans Affairs Pittsburgh Healthcare System in Pittsburgh, PA. Dr Hausmann was supported by VA Health Services Research and Development Career Development Awards (RCD 06-287 and ER 0280-1). The authors take full responsibility for the contents of this paper, which do not represent the views of the Department of Veterans Affairs or the United States Government. The authors would like to acknowledge the individual contributions of:
Rita Marsh, RN, MSN; Deborah Klinvex, BA; Tienna Luster; Beth Hall, RD; and Kathleen O’Malley, BA, BPhil.

\section{Disclosure}

The authors report no conflicts of interest in this work.

\section{References}

1. Centers for Disease Control and Prevention. National diabetes fact sheet: general information and national estimates on diabetes in the United States, 2007. Atlanta, GA: Department of Health and Human Services, Centers for Disease Control and Prevention; 2008.

2. Brancati FL, Kao WH, Folsom AR, Watson RL, Szklo M. Incident type 2 diabetes mellitus in African American and white adults: the Atherosclerosis Risk in Communities Study. JAMA. 2000;283(17): 2253-2259.

3. Brancati FL, Whelton PK, Kuller LH, Klag MJ. Diabetes mellitus, race, and socioeconomic status. A population-based study. Ann Epidemiol. 1996;6(1):67-73.

4. Harris MI. Epidemiological correlates of NIDDM in Hispanics, whites, and blacks in the US population. Diabetes Care. 1991;14(7): 639-648.

5. Robbins JM, Vaccarino V, Zhang H, Kasl SV. Excess type 2 diabetes in African-American women and men aged 40-74 and socioeconomic status: evidence from the Third National Health and Nutrition Examination Survey. J Epidemiol Community Health. 2000;54(11): 839-845.

6. McBean AM, Li S, Gilbertson DT, Collins AJ. Differences in diabetes prevalence, incidence, and mortality among the elderly of four racial/ ethnic groups: whites, blacks, Hispanics, and Asians. Diabetes Care. 2004;27(10):2317-2324.

7. Adams AS, Trinacty CM, Zhang F, et al. Medication adherence and racial differences in A1C control. Diabetes Care. 2008;31(5): 916-921.

8. Bertoni AG, Clark JM, Feeney P, et al. Suboptimal control of glycemia, blood pressure, and LDL cholesterol in overweight adults with diabetes: the Look AHEAD Study. J Diabetes Complications. 2008;22(1): $1-9$.

9. Boltri JM, Okosun IS, Davis-Smith M, Vogel RL. Hemoglobin A1c levels in diagnosed and undiagnosed black, Hispanic, and white persons with diabetes: results from NHANES 1999-2000. Ethn Dis. 2005;15(4): $562-567$.

10. Brown AF, Gregg EW, Stevens MR, et al. Race, ethnicity, socioeconomic position, and quality of care for adults with diabetes enrolled in managed care: the Translating Research Into Action for Diabetes (TRIAD) study. Diabetes Care. 2005;28(12):2864-2870.

11. de Rekeneire N, Rooks RN, Simonsick EM, et al. Racial differences in glycemic control in a well-functioning older diabetic population: findings from the Health, Aging and Body Composition Study. Diabetes Care. 2003;26(7):1986-1992.

12. Holcomb WL Jr, Mostello DJ, Leguizamon GF. African-American women have higher initial $\mathrm{HbA}_{1 \mathrm{c}}$ levels in diabetic pregnancy. Diabetes Care. 2001;24(2):280-283.

13. Wendel CS, Shah JH, Duckworth WC, Hoffman RM, Mohler MJ, Murata GH. Racial and ethnic disparities in the control of cardiovascular disease risk factors in Southwest American veterans with type 2 diabetes: the Diabetes Outcomes in Veterans Study. BMC Health Serv Res. 2006;6:58.

14. Harris MI, Eastman RC, Cowie CC, Flegal KM, Eberhardt MS. Racial and ethnic differences in glycemic control of adults with type 2 diabetes. Diabetes Care. 1999;22(3):403-408.

15. Bonds DE, Zaccaro DJ, Karter AJ, Selby JV, Saad M, Goff DC Jr. Ethnic and racial differences in diabetes care: The Insulin Resistance Atherosclerosis Study. Diabetes Care. 2003;26(4) $1040-1046$. 
16. Heisler M, Faul JD, Hayward RA, Langa KM, Blaum C, Weir D. Mechanisms for racial and ethnic disparities in glycemic control in middle-aged and older Americans in the health and retirement study. Arch Intern Med. 2007;167(17):1853-1860.

17. Bell RA, Summerson JH, Konen JC. Racial differences in psychosocial variables among adults with non-insulin-dependent diabetes mellitus. Behav Med. 1995;21(2):69-73.

18. Sequist TD, Adams A, Zhang F, Ross-Degnan D, Ayanian JZ. Effect of quality improvement on racial disparities in diabetes care. Arch Intern Med. 2006;166(6):675-681.

19. Kirk JK, D'Agostino RB Jr, Bell RA, et al. Disparities in HbA levels between African-American and non-Hispanic white adults with diabetes: a meta-analysis. Diabetes Care. 2006;29(9):2130-2136.

20. Quenan L, Remington P. Diabetes mortality trends in Wisconsin, 1979-1997: the increasing gap between whites and blacks. WMJ. 2000; 99(3):44-47.

21. Sanchez-Thorin JC. The epidemiology of diabetes mellitus and diabetic retinopathy. Int Ophthalmol Clin. 1998;38(2):11-18.

22. Krop JS, Coresh J, Chambless LE, et al. A community-based study of explanatory factors for the excess risk for early renal function decline in blacks vs whites with diabetes: the Atherosclerosis Risk in Communities study. Arch Intern Med. 1999;159(15):1777-1783.

23. Massing MW, Henley N, Biggs D, Schenck A, Simpson RJ Jr. Prevalence and care of diabetes mellitus in the Medicare population of North Carolina. Baseline findings from the Medicare Healthcare Quality Improvement Program. $N$ C Med J. 2003;64(2):51-57.

24. Kamel HK, Rodriguez-Saldana J, Flaherty JH, Miller DK. Diabetes mellitus among ethnic seniors: contrasts with diabetes in whites. Clin Geriatr Med. 1999;15(2):265-278.

25. Karter AJ, Ferrara A, Liu JY, Moffet HH, Ackerson LM, Selby JV. Ethnic disparities in diabetic complications in an insured population. JAMA. 2002;287(19):2519-2527.

26. Harris EL, Sherman SH, Georgopoulos A. Black-white differences in risk of developing retinopathy among individuals with type 2 diabetes. Diabetes Care. 1999;22(5):779-783.

27. Wong TY, Klein R, Islam FM, et al. Diabetic retinopathy in a multiethnic cohort in the United States. Am J Ophthalmol. 2006;141(3): 446-455.

28. Stephens GW, Gillaspy JA, Clyne D, Mejia A, Pollak VE. Racial differences in the incidence of end-stage renal disease in types I and II diabetes mellitus. Am J Kidney Dis. 1990;15(6):562-567.

29. Young BA, Maynard C, Reiber G, Boyko EJ. Effects of ethnicity and nephropathy on lower-extremity amputation risk among diabetic veterans. Diabetes Care. 2003;26(2):495-501.

30. Young BA, Maynard C, Boyko EJ. Racial differences in diabetic nephropathy, cardiovascular disease, and mortality in a national population of veterans. Diabetes Care. 2003;26(8):2392-2399.

31. The Diabetes Control and Complications Trial Research Group. The effect of intensive treatment of diabetes on the development and progression of long-term complications in insulin-dependent diabetes mellitus. N Engl J Med. 1993;329(14):977-986.

32. Sequist TD, Fitzmaurice GM, Marshall R, Shaykevich S, Safran DG, Ayanian JZ. Physician performance and racial disparities in diabetes mellitus care. Arch Intern Med. 2008;168(11):1145-1151.

33. Saydah S, Cowie C, Eberhardt MS, De Rekeneire N, Narayan KM. Race and ethnic differences in glycemic control among adults with diagnosed diabetes in the United States. Ethn Dis. 2007;17(3):529-535.

34. Glasgow RE, Fisher L, Skaff M, Mullan J, Toobert DJ. Problem solving and diabetes self-management: investigation in a large, multiracial sample. Diabetes Care. 2007;30(1):33-37.

35. Kurian AK, Borders TF. Racial and ethnic differences in the effects of regular providers and self-management education on diabetes preventive care. Ethn Dis. 2006;16(4):786-791.

36. Lee JA, Liu CF, Sales AE. Racial and ethnic differences in diabetes care and health care use and costs. Prev Chronic Dis. 2006;3(3): A85.
37. Oladele CR, Barnett E. Racial/ethnic and social class differences in preventive care practices among persons with diabetes. BMC Public Health. 2006;6:259.

38. Thackeray R, Merrill RM, Neiger BL. Disparities in diabetes management practice between racial and ethnic groups in the United States. Diabetes Educ. 2004;30(4):665-675.

39. Harris MI. Racial and ethnic differences in health care access and health outcomes for adults with type 2 diabetes. Diabetes Care. 2001;24(3):454-459.

40. Nwasuruba C, Osuagwu C, Bae S, Singh KP, Egede LE. Racial differences in diabetes self-management and quality of care in Texas. J Diabetes Complications. 2009;23(2):112-118.

41. DuBard CA, Yow A, Bostrom S, Attiah E, Griffith B, Lawrence W. Racial/ethnic differences in quality of care for North Carolina Medicaid recipients. NC Med J. 2009;70(2):96-101.

42. Bandura A. Social Foundations of Thought and Action: A Social Cognitive Theory. Englewood Cliffs, NJ: Prentice-Hall; 1986.

43. Whittemore R, D’Eramo Melkus G, Grey M. Metabolic control, self-management and psychosocial adjustment in women with type 2 diabetes. J Clin Nurs. 2005;14(2):195-203.

44. Gallant MP. The influence of social support on chronic illness self-management: a review and directions for research. Health Educ Behav. 2003;30(2):170-195.

45. Talbot F, Nouwen A, Gingras J, Gosselin M, Audet J. The assessment of diabetes-related cognitive and social factors: the multidimensional diabetes questionnaire. J Behav Med. 1997;20(3):291-312.

46. Toljamo M, Hentinen M. Adherence to self-care and social support. J Clin Nurs. 2001;10(5):618-627.

47. Glasgow RE, Toobert DJ, Hampson SE, Wilson W. Behavioral research on diabetes at the Oregon Research Institute. Ann Behav Med. 1995;17(1):32-40.

48. Hurley AC, Shea CA. Self-efficacy: strategy for enhancing diabetes self-care. Diabetes Educ. 1992;18(2):146-150.

49. Rosland AM, Kieffer E, Israel B, et al. When is social support important? The association of family support and professional support with specific diabetes self-management behaviors. J Gen Intern Med. 2008;23(12):1992-1999.

50. Sarkar U, Fisher L, Schillinger D. Is self-efficacy associated with diabetes self-management across race/ethnicity and health literacy? Diabetes Care. 2006;29(4):823-829.

51. Brody GH, Kogan SM, Murry VM, Chen YF, Brown AC. Psychological functioning, support for self-management, and glycemic control among rural African American adults with diabetes mellitus type 2. Health Psychol. 2008;27(1 Suppl):S83-S90.

52. Shaw BA, Gallant MP, Riley-Jacome M, Spokane LS. Assessing sources of support for diabetes self-care in urban and rural underserved communities. J Community Health. 2006;31(5):393-412.

53. Skelly AH, Marshall JR, Haughey BP, Davis PJ, Dunford RG. Self-efficacy and confidence in outcomes as determinants of self-care practices in inner-city, African-American women with non-insulindependent diabetes. Diabetes Educ. 1995;21(1):38-46.

54. Chlebowy DO, Garvin BJ. Social support, self-efficacy, and outcome expectations: impact on self-care behaviors and glycemic control in Caucasian and African American adults with type 2 diabetes. Diabetes Educ. 2006;32(5):777-786.

55. Spencer MS, Kieffer EC, Sinco BR, et al. Diabetes-specific emotional distress among African Americans and Hispanics with type 2 diabetes. J Health Care Poor Underserved. 2006;17(2 Suppl): 88-105.

56. Sevick MA, Zickmund S, Korytkowski M, et al. Design, feasibility, and acceptability of an intervention using personal digital assistant-based self-monitoring in managing type 2 diabetes. Contemp Clin Trials. 2008;29(3):396-409.

57. Stewart AL, Mills KM, King AC, Haskell WL, Gillis D, Ritter PL. CHAMPS physical activity questionnaire for older adults: outcomes for interventions. Med Sci Sports Exerc. 2001;33(7):1126-1141. 
58. Rigler SK, Studenski S, Wallace D, Reker DM, Duncan PW. Co-morbidity adjustment for functional outcomes in communitydwelling older adults. Clin Rehabil. 2002;16:420-428.

59. Beck AT, Steer RA, Brown GK. BDI-II Manual. San Antonio, TX: Harcourt Brace \& Co; 1996.

60. Signorello LB, Schlundt DG, Cohen SS, et al. Comparing diabetes prevalence between African Americans and Whites of similar socioeconomic status. Am J Public Health. 2007;97(12):2260-2267.

61. Link CL, McKinlay JB. Disparities in the prevalence of diabetes: is it race/ethnicity or socioeconomic status? Results from the Boston Area Community Health (BACH) survey. Ethn Dis. 2009;19(3):288-292.

62. Laveist TA, Thorpe RJ Jr, Galarraga JE, Bower KM, Gary-Webb TL. Environmental and socio-economic factors as contributors to racial disparities in diabetes prevalence. J Gen Intern Med. 2009;24(10): 1144-1148.
63. Landrine H, Corral I. Separate and unequal: residential segregation and black health disparities. Ethn Dis. 2009;19(2):179-184.

64. O’Dell K, O'Dell M. Socio-ecological resources for diabetes self-management. J Miss State Med Assoc. 2006;47(4):99-103.

65. Glasgow RE, Strycker LA, Toobert DJ, Eakin E. A social-ecologic approach to assessing support for disease self-management: the Chronic Illness Resources Survey. J Behav Med. 2000;23(6):559-583.

66. Polonsky WH, Anderson BJ, Lohrer PA, et al. Assessment of diabetesrelated distress. Diabetes Care. 1995;18(6):754-760.

Patient Preference and Adherence

\section{Publish your work in this journal}

Patient Preference and Adherence is an international, peer-reviewed, open access journal that focusing on the growing importance of patient preference and adherence throughout the therapeutic continuum. Patient satisfaction, acceptability, quality of life, compliance, persistence and their role in developing new therapeutic modalities and compounds to optimize clinical outcomes for existing disease states are major areas of interest. This journal has been accepted for indexing on PubMed Central. The manuscript management system is completely online and includes a very quick and fair peer-review system. Visit http://www.dovepress.com/ testimonials.php to read real quotes from published authors.

Submit your manuscript here: http://www.dovepress.com/patient-preference-and-adherence-journal 